Espacio y Desarrollo No 35, 2020, pp. 121-148 (e-ISSN 2311-5734)

https://doi.org/10.18800/espacioydesarrollo.202001.005

\title{
AliANZAS Y CONFLICTOS EN UN TERRITORIO DEL AGUA: EL CASO DE LA SUbCUENCA DEL RÍo SANTA EULALIA
}

\author{
Sofia Castro Salvador \\ Université Paris 1 Panthéon-Sorbonne \\ Instituto de Ciencias de la Naturaleza, Territorio y Energías Renovables \\ (INTE-PUCP) \\ castro.sa@pucp.pe
}

\section{RESUMEN}

La participación es considerada como uno de los elementos clave para la descentralización en la gestión del agua y como un medio para mejorar la eficacia y reducir las desigualdades territoriales. En un territorio de agua encontramos diversos actores con intereses, demandas y agendas en relación con el agua. Esto puede generar tensiones por un recurso que se vuelve cada vez más demandado debido a los diversos usos (agrícola, urbano, industrial, turístico) y en las diferentes instancias de gestión (público, privado y comunal). Este articulo intenta mostrar las relaciones de poder en un territorio de agua, es decir, cómo los poderes locales participan en la gestión del agua, cómo coordinan entre ellos y con otros actores en diversas escalas. En estas relaciones de poder se observan cooperaciones, alianzas en consolidación, pero también tensiones entre los actores, conflictos por los territorios, defensas por las territorialidades y superposiciones de proyectos. Esto debido a la limitada coordinación entre los actores locales ya que cada uno maneja agendas individuales y tiene intereses en juego lo que no permite una real participación ni consolidación de alianzas. Lo que resulta en un verdadero desafío para la gobernanza del agua y para el territorio.

Palabras clave: AGUA, TERRITORIO, CONFLICTOS, ACTORES, ALIANZAS.

\section{Alliances and conflicts in a water territory: the case of Santa Eulalia sub-basin}

\section{Abstract}

Participation is considered a key element for decentralization in water management and as a means for efficiency as well as for the reduction of territorial inequalities. In a water territory, we find diverse actors with diverse interests, demands and agendas in relation to water. This could lead to tensions for a resource that becomes more and more demanded due to the different uses (agricultural, urban, industrial, tourist) and in the different management instances

\footnotetext{
1 Este artículo se desprende de uno de los capítulos de la tesis de maestría sustentada en setiembre de
} 2016 en París, en el marco de la Maestría de Geografía de la Université de Paris 1 Panthéon-Sorbonne. 
(public, private and communal). This article attempts to show the power relations in a water territory, how local powers participate in water management, and how they coordinate among themselves and with other actors at various scales.

These power relations show cooperation, alliances to be consolidate, but tensions also between the actors, conflicts between territories, struggles for territorialities and overlapping projects. This because of the limited coordination between local actors, since each one is dominated by their individual agendas and has interests at stake, which does not allow effective participation or consolidation of alliances. This is a real challenge for water governance and for the territory. Keywords: water, territory, conflicts, actors, alliances.

\section{INTRODUCCIÓN}

A partir de la década de 1980, se empieza a cuestionar, a nivel mundial, el rol centralista de los países y su fracaso en la gestión de los recursos naturales a partir de sus políticas top-down (Andersson \& Ostrom, 2008, p. 72). En particular, se cuestionó el rol del Estado central para gestionar de manera eficaz los recursos hídricos. Desde entonces, se incorporan en las legislaciones relacionadas con los recursos naturales, en particular, el agua, principios como la participación, la descentralización y la eficacia.

En el caso del Perú, en 2009 se aprueba una nueva ley de recursos hídricos que deroga la Ley General de Aguas de 1969, una ley con un sesgo agrario y centralista (Zegarra, 2005). La nueva ley incluye dentro de sus principios que rigen la gestión del agua, a la gestión integrada del recurso, la participación, la descentralización y la eficacia. Además, se resalta que la unidad de gestión es la cuenca, y es de carácter multisectorial para lo cual crea diversos instrumentos como el Sistema Nacional de Gestión de Recursos Hídricos (SNGRH), los Consejos de Recursos Hídricos de Cuenca (CRHC), los derechos de uso de agua (DUA) entre otros.

La gestión integrada de recursos hídricos $(\mathrm{GIRH})^{2}$, aparece al final del siglo XX como una herramienta que responde a los desafíos de la unidad de gestión: la cuenca (GWP, 2000; Perez-Sanchez \& Senent-Aparicio, 2015). Sin embargo, algunos autores critican esta respuesta global para enfrentar el problema del agua. Biswas (2004) afirma que la integración y la coordinación de la gestión del agua no son posibles debido a la gran cantidad de instituciones y de actores, y sobre todo porque cada uno tiene sus propios intereses y usos en relación con el agua.

\footnotetext{
2 La gestión Integrada de Recursos Hídricos (GIRH) es «un proceso que promueve el desarrollo y manejo coordinados del agua, la tierra y otros recursos relacionados, con el fin de maximizar el bienestar económico y social resultante de manera equitativa, sin comprometer la sostenibilidad de los ecosistemas vitales» (GWP, 2000, p. 24).
} 
Asimismo, la gestión de cuencas puede ser visto como un instrumento de descentralización debido a que el gobierno central transfiere funciones y decisiones a estas unidades más cercanas a la población, bajo el principio de subsidiariedad. De hecho, la descentralización en la gestión de recursos se presenta como una «herramienta para la reducción de desigualdades territoriales y socioeconómicas que permita una distribución más equitativa de los recursos sobre el conjunto del territorio» (Bey, 2010, p. 131).

La crisis del agua es, según una encuesta de percepción del Global Risk Report 2020, la de mayor impacto para la sociedad (World Economic Forum, 2020), seguido de otras crisis como las climáticas, sanitarias, económicas, etc. Algunos autores señalan que la crisis del agua es una crisis de gestión del recurso (Bouguerra, 2003; Mikail, 2005) ya que es tratada de manera sectorial y fragmentada (Edelenbos \& Teisman, 2011; Trottier, 2008). Otros autores señalan que la crisis del agua (OECD, 2012) es una crisis de gobernanza (Edelenbos \& Teisman 2011; OECD 2012) debido a la necesidad de articular y coordinar entre los diversos usuarios de agua en diversas escalas.

En una cuenca, definida como aquella porción de un espacio delimitado por las líneas divisorias de agua, encontramos actores que utilizan el agua y los recursos asociados a él, y de acuerdo con sus actividades productivas y domésticas lo transforman y se apropian de este espacio. Por ello, hablamos de un territorio de agua, de análisis y de acción pública (Charnay, 2010; Ghiotti, 2006; Haghe \& Ghiotti, 2004) donde las dimensiones políticas, administrativas, socioeconómicas y ambientales se interrelacionan fuertemente.

En este territorio, construido socialmente, los actores se integran, articulan y coordinan para el uso del agua. Sin embargo, también es un campo de tensiones y competencias por un recurso clave para diversos usos. Esto representa un desafío para los poderes públicos (Ghiotti, 2006, p. 10) y locales debido a los actores deben conservar los recursos hídricos y al mismo tiempo responder a estos diferentes usos del agua, y en estas acciones e interacciones se reflejan las relaciones de poder implicadas en las escalas espaciales y temporales (Harvey, 1998, p. 250).

Es en este contexto que nos preguntamos ¿̨ide qué manera los poderes locales participan en la gestión del agua? ¿cómo estos poderes coordinan entre ellos y con otros actores que pertenecen a otras escalas? ¿es que la mayor participación y la diversidad de actores hace que la gestión del agua sea compleja? ¿qué tipo de alianzas se generan o que tipo de conflictos se producen? ¿Los actores descentralizados tienen un poder real en la gestión del agua? Responder estas preguntas, nos lleva a preguntarnos ¿quiénes son los actores de esta gestión?, ¿cómo utilizan las aguas del río? ¿su uso crea conflictos sobre el agua?

Para ilustrar la complejidad de la gestión actual de los recursos hídricos en un territorio del agua y responder estas preguntas, analizaremos el caso de la subcuenca del río Santa Eulalia (ver mapa 1), en la periferia de Lima (aproximadamente a unos 
50 kilómetros del centro de Lima), donde más del 50\% del agua transita por este rio ${ }^{3}$ destinada a aproximadamente 10 millones de habitantes de la metrópoli de Lima ${ }^{4}$. El rio Santa Eulalia es el principal afluente del Río Rímac con una superficie de $1077,38 \mathrm{~km}^{2}$ que representa el 30,75\% del área total de la cuenca del río Rímac.

Este articulo está dividido en tres partes. En una primera parte, explicaremos la metodología utilizada para responder estas preguntas planteadas, luego describiremos la zona de estudio. En la siguiente analizamos las acciones de los diversos actores implicados en la subcuenca, sus asociaciones, sus alianzas, así como también los conflictos que se crean a partir del uso y gestión del agua, y finalmente unas reflexiones finales a modo de conclusión.

\section{Metodología}

Para responder a las preguntas planteadas, elegimos el uso de metodología cualitativa a través de la aplicación de instrumentos como las entrevistas a profundidad y un taller participativo con actores de la subcuenca de Santa Eulalia, que son parte del Comité Coordinador y Asesor del Programa Agua, Clima y Desarrollo (PACyD) de Global Water Partnership5 (GWP).

\subsection{Entrevistas a profundidad}

Entre febrero y mayo de 2016, en el marco de la realización de mi tesis de maestría de Geografía en la Université de Paris 1 Panthèon-Sorbonne, realicé dieciocho entrevistas a profundidad con actores locales, regionales y nacionales vinculados a la gestión del agua. El objetivo central de la entrevista fue entender el rol del actor entrevistado en la gestión del agua y sus interacciones con otros actores de la subcuenca y de otras escalas. Todas las entrevistas se realizaron con el consentimiento informado de los actores y se le asignó un código a cada actor con el fin de mantener el anonimato y la confidencialidad de la información.

\footnotetext{
3 Lima depende de tres cuencas: Rímac, Chillón y Lurín. La primera es la más importante para la metrópoli en lo que se refiere al abastecimiento de agua, pero también es la más contaminada (MINAM, 2013). Santa Eulalia es la subcuenca más importante de la cuenca del Rímac.

4 Lima tiene 43 distritos y la provincia constitucional del Callao tiene 7 distritos más. Las elecciones de las autoridades locales se dan cada cuatro años.

5 Global Water Partnership (GWP) es una organización mundial (con base en Estocolmo) intergubernamental, formada por diversas organizaciones vinculadas en la gestión del agua, que sostienen, facilitan y apoyan el proceso de cambio hacia la gestión integrada de recursos hídricos (GIRH).
} 
Tabla 1. Lista de entrevistados

\begin{tabular}{llc}
\hline \multicolumn{1}{c}{ Actor } & \multicolumn{1}{c}{ Organización } & $\begin{array}{c}\text { Número de } \\
\text { entrevistas }\end{array}$ \\
\hline Funcionario & Autoridad Nacional del Agua & 4 \\
\hline Funcionario & Ministerio de Agricultura y Riego & 2 \\
\hline Funcionario & Gobierno Regional de Lima & 1 \\
\hline Académico & PUCP & 2 \\
\hline Funcionario & Sedapal & 1 \\
\hline Gerente & Mancomunidad Municipal del Valle de Santa Eulalia & 1 \\
\hline Vice-presidente & Asociación de Usuarios del subdistrito de riego del Rimac & 1 \\
\hline Presidente & Comité de Usuarios de Agua de Parca & 1 \\
\hline Presidente & Asociación de Productores Agrarios & 1 \\
\hline Presidente & Asociación de Comunidades Campesinas Nor Huarochiri & 1 \\
\hline Coordinador & & 1 \\
\hline Presidente & Presidente Comunidad Campesina San Pedro de Casta & 1 \\
\hline Presidente & $\begin{array}{l}\text { Comité de Recursos Hídricos Comunidad Campesina San Pedro } \\
\text { de Casta }\end{array}$ & \\
\hline
\end{tabular}

\subsection{Taller participativo}

El taller con actores de la subcuenca de Santa Eulalia se desarrolló el 23 de junio de 2016 como una actividad incluida en la reunión del Comité Coordinador y Asesor del PACyD ${ }^{6}$ de GWP. El objetivo de este taller fue conocer el nivel de relacionamiento y el nivel de influencia de los actores presentes en la subcuenca con el fin de construir un mapa de actores. En dicho taller participaron aproximadamente treinta personas (representantes) de diversas organizaciones locales, regionales y nacionales y que tenían algún nivel de intervención en la subcuenca de Santa Eulalia.

El taller inició dando las pautas para la dinámica del taller. En primer lugar, se les explicó el objetivo de la dinámica y el uso de las tarjetas (cortadas en forma de triángulo). Los colores de las tarjetas estaban relacionados con el nivel de contacto (amarilla: no hay contacto, verde: contacto inicial, rosada: contacto avanzado) mientras que el tamaño del triángulo con el tipo de influencia (pequeńo: poca influencia, mediano: mediana influencia, grande: gran influencia). Luego se les planteó unas primeras preguntas

\footnotetext{
6 Agradezco a GWP por permitirme realizar esta actividad en una de sus reuniones del Comité. Debo señalar que el interés por estudiar esta subcuenca tiene su origen desde 2012 donde empecé a conocer la subcuenca y luego entre 2014 y 2015 asumí la coordinación de dicho programa. Esta experiencia me permitió conocer la problemática y observar la articulación entre los diferentes actores.
} 
de inicio: ¿qué actores se encuentran en la subcuenca? y ¿cómo se relacionan con otros actores? (paso 1 de la tabla 2) para trabajarla en grupos pequeńos y discutir entre ellos.

En un segundo momento, se pidió a los actores dialogar con actores de otros grupos y discutir la ubicación espacial de los actores identificados (paso 2). En el paso 3, los actores debían colocar la tarjeta (triangulo que representara a la vez: nivel de influencia y tipo de contacto) con el nombre del actor escrito en el triangulo sobre el papelografo de acuerdo con la escala ${ }^{7}$ correspondiente (local-distrital, regional, subcuenca-cuenca, nacional).

Finalmente, en una suerte de plenaria, los participantes debían describir el nivel de relacionamiento de los actores (si tenían alianzas o si identificaban conflictos) y porqué ubicaban la tarjeta en esa escala (paso 4). Esto significó discusiones y acuerdos acerca de donde ubicar la tarjeta y los diversos puntos de vista sobre los actores acerca de las alianzas y conflictos identificados.

Tabla 2. Resumen de los pasos metodológicos para el mapeo de actores

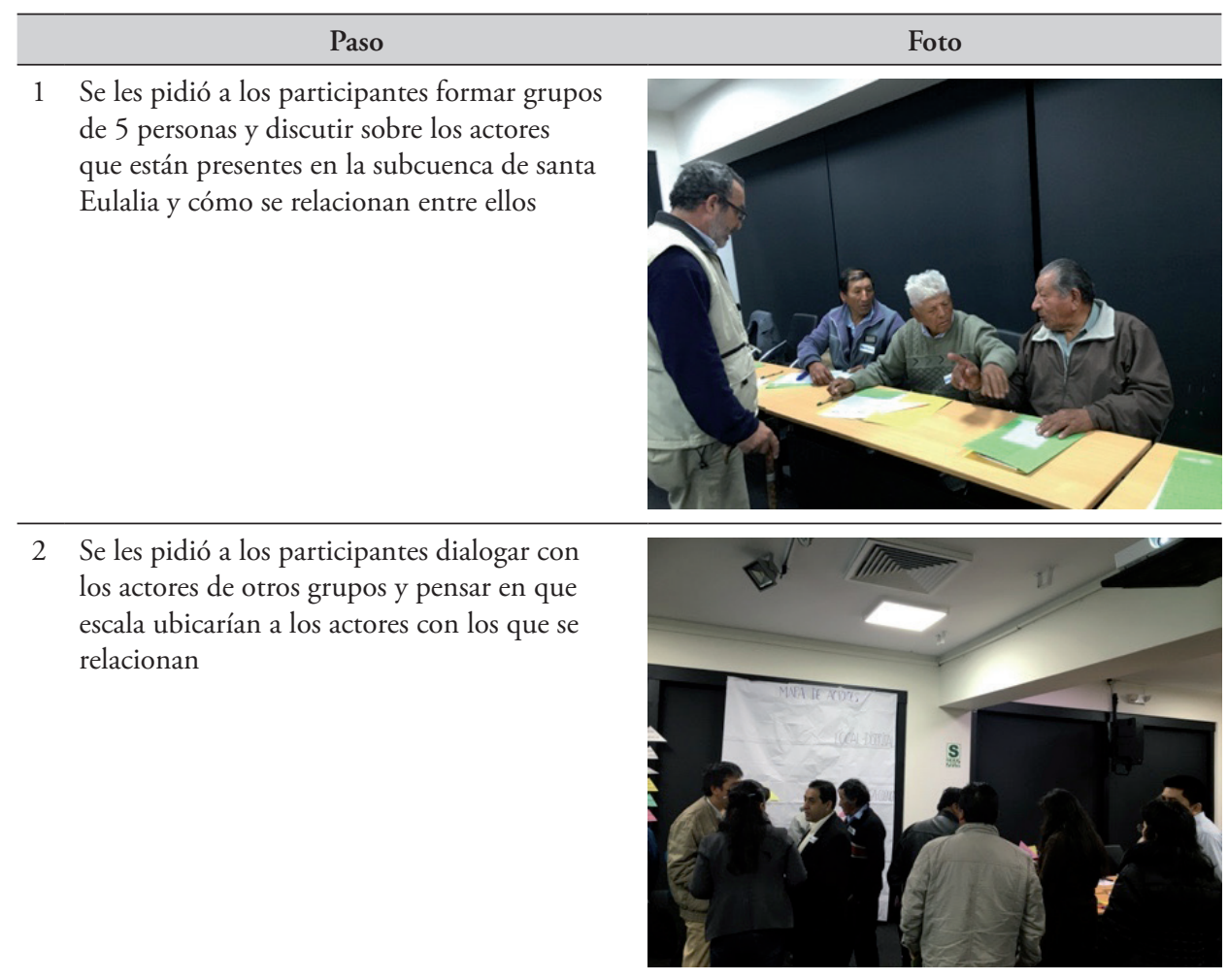

7 Cabe señalar que los mismos actores identificaron y propusieron las escalas. 


\section{Paso}

\section{Foto}

3 Los participantes colocan en un papelógrafo a los diversos actores identificados de acuerdo con tres criterios:

1) Escala de acción de los actores (localdistrital, subcuenca, regional y nacional)

2) Nivel de influencia

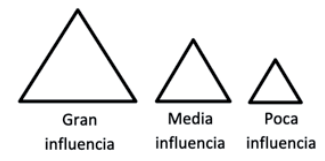

3) Tipo de contacto
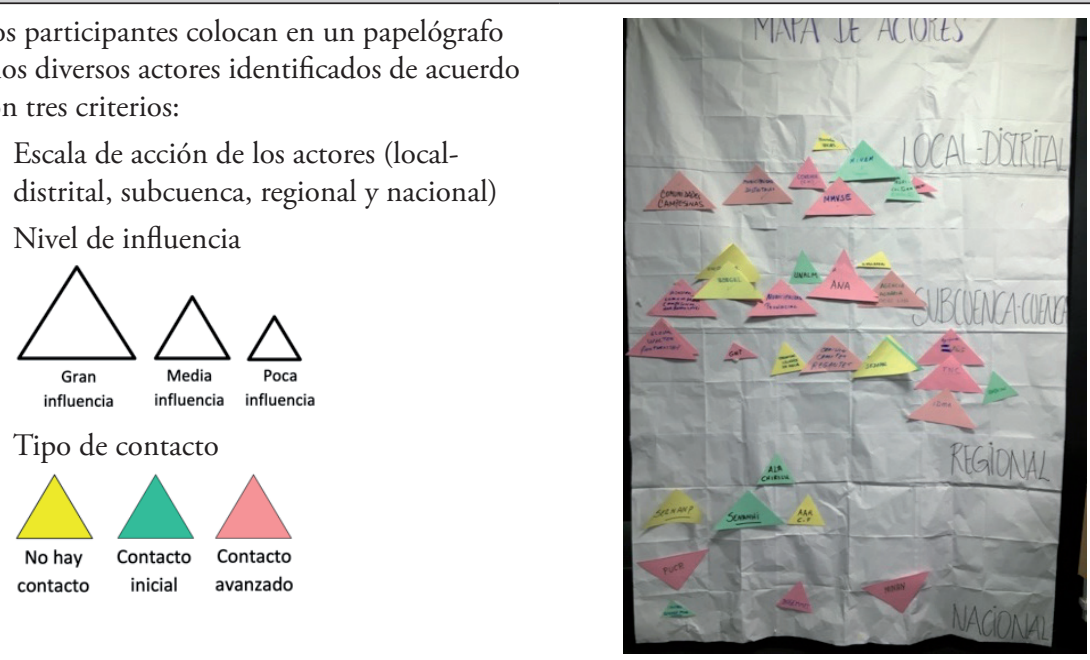

4 El nivel de relacionamiento (cooperación/ alianza, en proceso de consolidación, inestable, conflictiva). Se le pidió a los actores que mientras iban ubicando a los actores en el papelógrafo explicaran por qué los ponían en este lugar.

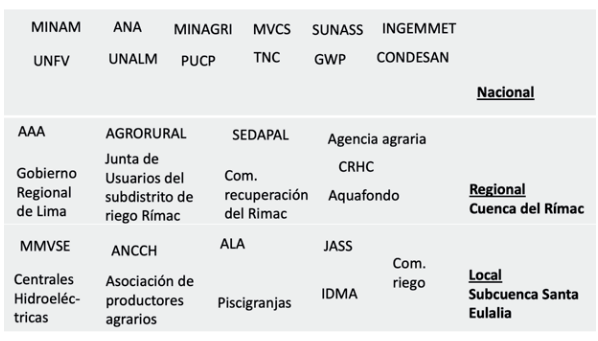

Para la construcción final del mapa de actores que presentamos en la tercera sección (ver figura 2), donde se incluye el nivel de relacionamiento y de influencia, se complementó con las entrevistas a profundidad realizadas.

Asimismo, otro instrumento importante fue la observación participante que realizamos tanto en las mismas comunidades de la subcuenca como en las reuniones mensuales del Comité Coordinador y Asesor del PACyD de GWP, grupo donde participan todos los actores de la subcuenca.

\section{Estudio de caso: la subcuenca de Santa Eulalia}

El río Santa Eulalia transita por el territorio de la provincia de Huarochiri (región Lima) y nueve distritos ${ }^{8}$ ubicados en la misma provincia. Estos distritos están situados por encima de los 900 metros sobre el nivel del mar, en la gran periferia de Lima.

8 El distrito es la organización político-administrativo más pequeña en el Perú. Cada distrito está dirigido por una municipalidad. 
Según las proyecciones del INEI (2015), su población es de aproximadamente 33985 personas 9 . Asimismo, la cuenca cuenta con 14 comunidades campesinas, ${ }^{10} 4$ centrales hidroeléctricas, 22 presas, cerca de 20 piscigranjas y diversos centros de recreación y de turismo de fin de semana (Castro, 2016).

La actividad principal, a lo largo del río Santa Eulalia, está basada principalmente en una economía de subsistencia, caracterizado por la pequeña agricultura. En la parta alta de la cuenca predomina la ganadería lechera. En la zona media y baja se desarrolla la fruticultura (palta y chirimoya). A lo largo del río y sus afluentes, se encuentran varias piscigranjas (veinte en promedio) pero la mayoría de ellas no funciona. Además, la cuenca es el marco de operación de varias centrales hidroeléctricas importantes para la generación de energía a escala metropolitana y nacional. Es así como el río Santa Eulalia se posiciona como un espacio estratégico para asegurar la sostenibilidad de la metrópoli, en términos de agua, de energía y de alimentación, aunque este último en menor medida (Castro, 2016).

\subsection{El programa Agua, Clima y Desarrollo (PACyD) de GWP Sudamérica en la subcuenca de Santa Eulalia}

A finales de 2013, GWP lanza su programa mundial Agua, Clima y Desarrollo (PACyD) en Sudamérica y elige a la subcuenca de Santa Eulalia, debido a su carácter estratégico de aprovisionamiento de agua y energía para la ciudad de Lima, para realizar este programa piloto. El objetivo general del programa es "contribuir a una mejor gobernanza del agua en el Perú demostrando que la interacción transectorial es una estrategia efectiva para alcanzar seguridad hídrica y desarrollar resiliencia al cambio climático para el desarrollo socioeconómico sostenible».

El PACyD se encuentra en interacción constante con diversos actores de diferentes niveles de decisión y de organización del territorio. Los miembros representan en parte a las instituciones públicas y están interesados en la revisión de dispositivos, su connotación territorial y/o política y en la posibilidad que los acuerdos que se logren en diversas escalas espaciales (local, regional y nacional) y temporales, permitan la creación de instancias multisectoriales, multiescalares y de reproducir la experiencia en otros territorios.

\footnotetext{
9 El distrito de Santa Eulalia (rio abajo) tiene 11787 habitantes y los otros 8 distritos tienen 22198 habitantes.

${ }^{10}$ Las comunidades campesinas son «organizaciones de interés público, con existencia legal y personería jurídica, integradas por familias que habitan y controlan determinados territorios, ligadas por vínculos ancestrales, sociales, económicos y culturales, expresados en la propiedad comunal de la tierra, el trabajo comunal, la ayuda mutua, el gobierno democrático y el desarrollo de actividades multisectoriales, cuyos fines se orientan a la realización plena de sus miembros y del país» (Ley General de Comunidades Campesinas 24656,1987$)$.
} 
Figura 1. Mapa de ubicación

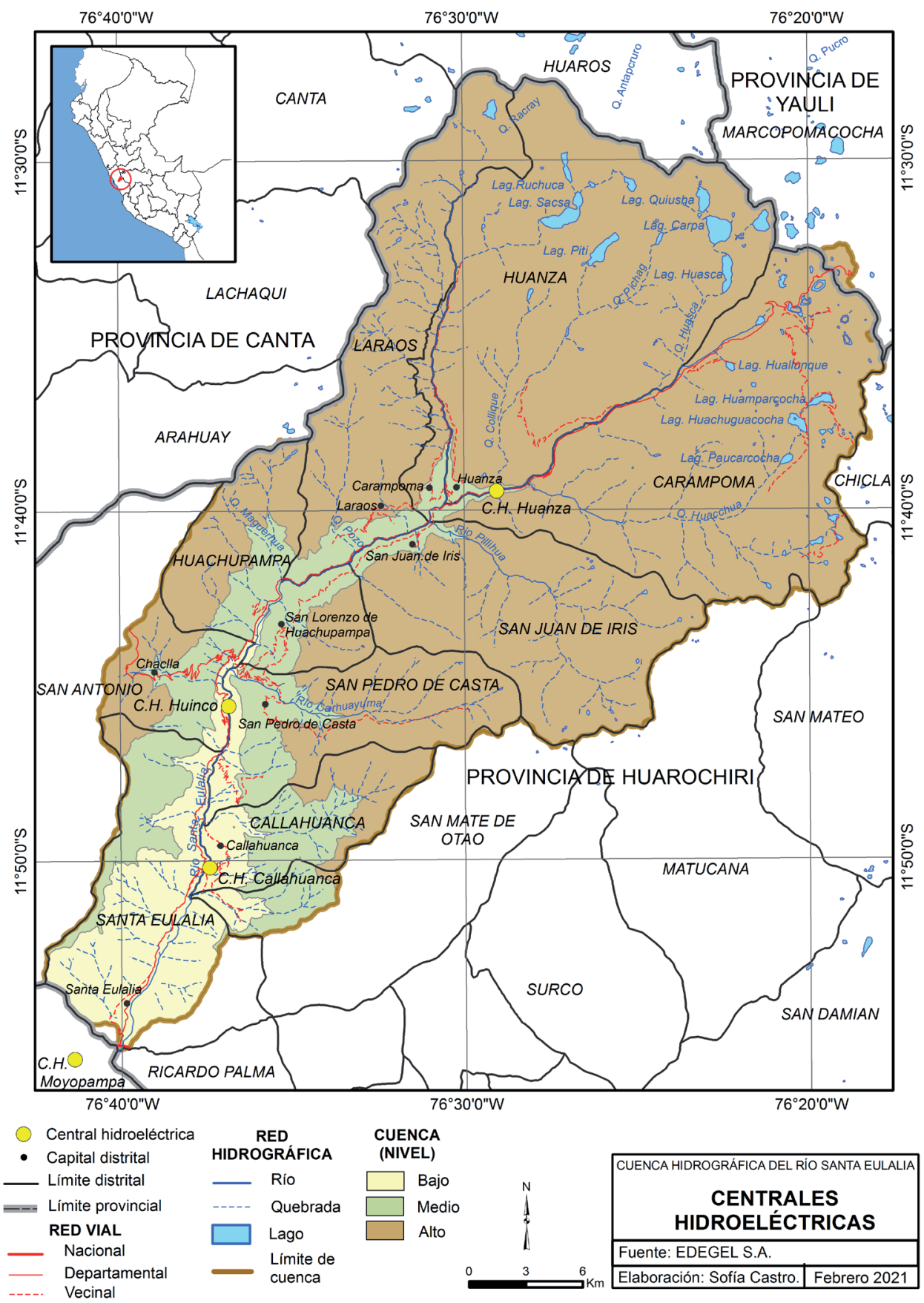


Para promover la participación activa de los diversos actores en la subcuenca, el PACyD crea un Comité Coordinador y Asesor donde se encuentra los diferentes ministerios relacionados con la gestión del agua (MINAGRI, MINAM, MINEM), la Autoridad Nacional del Agua (ANA) y sus órganos desconcentrados, las universidades (PUCP, UNALM, UNFV), Sedapal (Servicio de Agua Potable y Alcantarillado de Lima), empresas hidroeléctricas (Edegel y CONENHUA), ONG (Agua Limpia, Yacunahui, Soluciones Prácticas, etc.), así como los actores principales de la subcuenca, las comunidades campesinas y los gobiernos locales y sus asociaciones ACCNH y la MMVSE, ubicados en el territorio de la subcuenca (ver figura 1).

Figura 2. Integrantes del Grupo Especializado de Trabajo del PACyD, según escalas de intervención
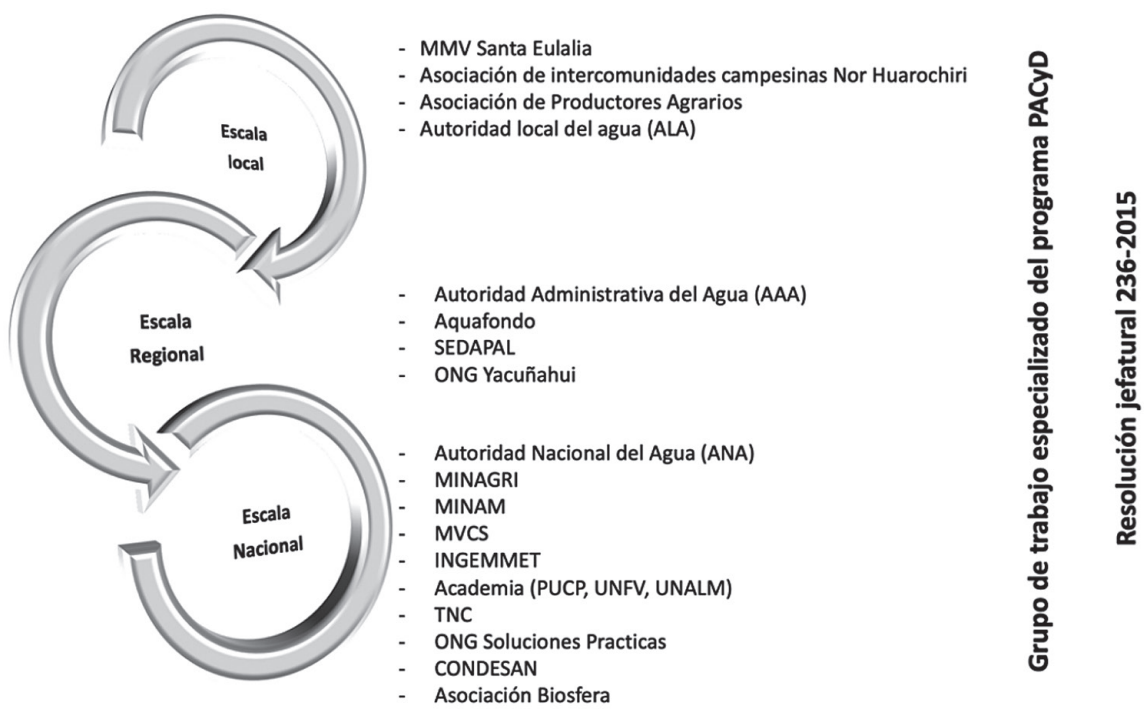

En 2015, la ANA formaliza al Comité Coordinador y Asesor como Grupo de Trabajo Especializado ${ }^{11}$ (ver figura 1) de la subcuenca, encargado de elaborar la estrategia de Gestión integrada de recursos hídrica de la subcuenca con el fin de ser un insumo que contribuya al Plan de Gestión del Consejo de Recursos Hídricos de Cuencas (CRHC) del Chillón, Rimac y Lurin (CHIRILU). Desde 2019, este grupo de trabajo especializado se ha convertido en un grupo de trabajo multisectorial ${ }^{12}$ del CRCH del CHIRILU.

\footnotetext{
${ }^{11}$ Resolución Jefatural 236-2015-ANA.

${ }^{12}$ http://observatoriochirilu.ana.gob.pe/informe/grupo-de-trabajo-multisectorial-de-la-subcuenca-delrio-santa-eulalia
} 
Figura 3. Taller organizado por GWP en junio de 2016 con el Grupo de Trabajo Especializado

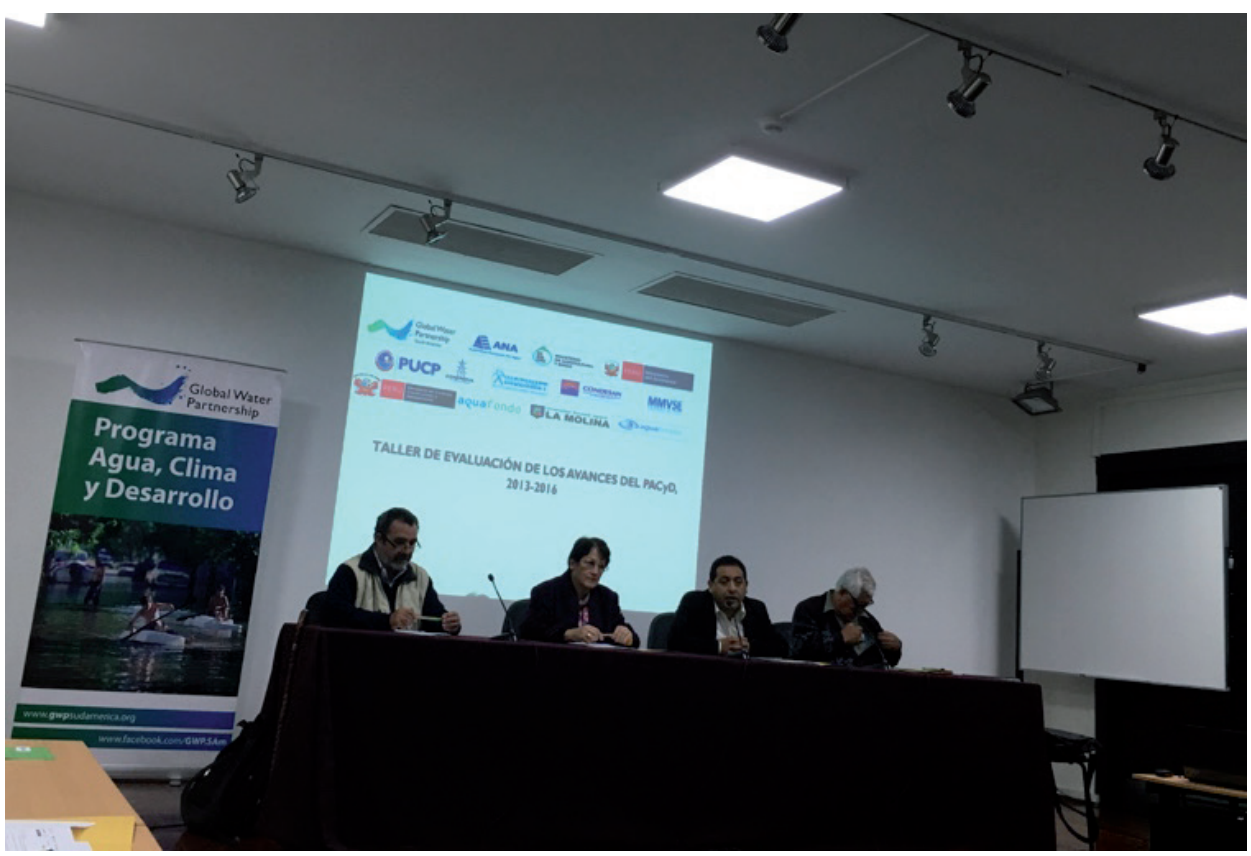

Este grupo de trabajo tiene la característica de reunirse mensualmente para discutir los avances y planes del PACyD. Las decisiones se toman en conjunto y se proponen nuevas de manera consensuada. Sin embargo, al inicio del programa, las características más comunes de los actores de la subcuenca eran la ausencia de dialogo, la desconfianza y la limitada coordinación (EE06). El programa empezó la implementación ${ }^{13}$ con un conjunto de talleres de sensibilización dirigido a los municipios y a las comunidades campesinas con el fin de mejorar los niveles de coordinación y participación de los actores en los diversos espacios. La temática de estos talleres estaba enfocada en el tema de agua, cambio climático y riesgos asociados. Asimismo, se ponía en evidencia la importancia de los recursos hídricos y de la subcuenca de Santa Eulalia para una metrópoli, como Lima. También, se llevó a cabo talleres y reuniones con los distintos sectores (ministerios y órganos adscritos) encargados de las políticas relacionadas con el recurso hídrico.

\footnotetext{
${ }^{13}$ Cabe señalar que previo a la implementación, se realizó un taller inicial en Chosica, con la mayoría de los actores que actualmente forman parte del Comité Coordinador y Asesor del PACyD para hacer un ajuste en el diseño del programa, ya que el $\mathrm{PACyD}$ es parte de un programa mundial que se implementa en otras regiones del mundo. Para el caso de Santa Eulalia, se hicieron muchos ajustes para tratar de adaptarlo al contexto de la subcuenca.
} 
El programa tiene un componente importante de planificación para el desarrollo cuyo objetivo es fortalecer la relación entre la acción pública, los diversos espacios intersectoriales existentes y la organización del territorio. Asimismo, fue necesario comprender las confrontaciones e interacciones entre todos los actores del territorio con el fin de diseñar de manera participativa las estrategias de intervención en temas como la conservación de agua y de suelo, los servicios ecosistémicos, los proyectos «no - low regrets» ${ }^{14}$, el conocimiento y la cultura del agua. Además, el programa está interesado en contribuir en las políticas públicas basado en las evidencias científicas y de investigación, que se realicen bajo el marco del PACyD.

\section{LA COMPLEJIDAD EN LAS INTERACCIONES DE LOS ACTORES DE LA subcuenca de Santa Eulalia}

Nuestro análisis se centra en dos actores clave de la subcuenca de Santa Eulalia, la Mancomunidad Municipal del Valle de Santa Eulalia (MMVSE) y la Asociación de Comunidades Campesinas Nor-Huarochíri (ACCNH). La MMVSE se crea en 2012 como iniciativa de los ocho distritos que se encuentran en la subcuenca ${ }^{15}$ : Laraos, Callahuanca, Carampoma, Huachupampa, Huanza, San Antonio de Chaclla, San Juan de Iris y San Pedro de Casta. El propósito de formar la mancomunidad es garantizar la continuidad de las gestiones locales independiente de los gobernantes locales de turno, aunque el solo hecho de reunirse no lo garantiza. En la MMVSE, no todos los alcaldes participan activamente. Sin embargo, resulta clave el rol del presidente de la Mancomunidad. En el periodo 2015-2019, el alcalde del distrito de Laraos fue elegido presidente de la MMVSE y durante su gestión promueve activamente labores de siembra y cosecha en la parte alta de la cuenca (EE11) cuyo objetivo era contribuir en la conservación de los suelos y en la recarga hídrica de la parte alta de la subcuenca (EE06).

El funcionamiento de esta organización se basa en el cumplimiento de los compromisos acordados de manera conjunta con todos los alcaldes. Uno de estos acuerdos es contribuir mensualmente con un aporte monetario para solventar varios gastos, uno de ellos, el pago mensual del gerente general contratado para la gestión de los proyectos. El rol del gerente elegido es fundamental, ya que debe tener capacidad de iniciativa, de articulación y de acción con otras instituciones en diversas escalas, incluso más allá de la subcuenca de Santa Eulalia. Sin embargo, los acuerdos no siempre se cumplen, los aportes no eran enviados con regularidad y no todos cumplían. A pesar de esto, el gerente elegido durante este periodo siguió gestionando y participando, en los diversos espacios en donde representaba a la MMVSE.

\footnotetext{
${ }_{14}$ Proyectos y medidas que deben implementarse, independientemente de los efectos del cambio climático.

${ }^{15}$ Aunque los límites político-administrativos no coinciden con los límites de la subcuenca de Santa Eulalia.
} 
Los principales ejes de acción de la MMVSE son el ordenamiento territorial, infraestructura vial e hidráulica, desarrollo de cadenas productivas, promoción turística y gestión ambiental de la subcuenca. Uno de sus principales proyectos comprende la reforestación de 10 hectáreas de las partes altas de la subcuenca con una especie nativa conocida como «quenuales» (sp polylepis), que tiene como fin generar ingresos económicos y contribuir a la regulación hídrica. La MMVSE ha logrado conseguir dos fondos del Fondo de Promoción a la Inversión Pública Regional y Local (FONIPREL) ${ }^{16}$ para realizar los estudios de preinversión de un proyecto en la margen derecha del río y para el mejoramiento de las redes vial vecinales (de la troncal hacia los pueblos) de la margen izquierda del río.

Adicionalmente, en la margen derecha del río Santa Eulalia, la MMVSE viene elaborando el proyecto «Sistema de riego Chinchan». Este proyecto consiste en extraer agua de las alturas del distrito de Laraos, específicamente de dos fuentes de agua, cerca de la laguna Quiulacocha ${ }^{17}$ y llevar el agua hacia la zona de Chaclla ${ }^{18}$, a lo largo de 37 kilómetros por un sistema de canales con fines productivos (EE11).

Por su parte, la Asociación de Comunidades Campesinas Nor-Huarochíri (ACCNH) se crea en 2015, el cual comprende a 14 comunidades campesinas y sus anexos, con aproximadamente 6500 comuneros. De acuerdo con el presidente ${ }^{19}$ de dicha asociación, desde el año 2011, tenían la necesidad de unirse para trabajar e impulsar de manera conjunta diversos proyectos para conseguir financiamiento. Su interés se encuentra en la ejecución del proyecto "CHICOC-COCHAVIJILA» el cual quiere dotar de agua a todas las comunidades de la margen derecha (COCHAVIJILA ${ }^{20}$ ) e izquierda $\left(\mathrm{CHICOC}^{21}\right.$ ) (ver mapa 2). En la margen izquierda del río Santa Eulalia, el proyecto Chicoc tiene previsto proveer de agua a seis comunidades (Carampoma, Huachupampa, Iris, Casta, Otao y Callahuanca) a través de canales de riego (EE12, EE18). Para ello, la ACCNH solicitó el permiso para el uso de dos 2 lagunas: Tuctucocha y Vilacocha que se encuentran en el territorio de la comunidad campesina de Carampoma. Sin embargo, en 2015, la comunidad campesina de San Juan de Iris señaló que estas dos lagunas se encuentran dentro de su territorio. De acuerdo con los límites referenciales o censales, estas lagunas pertenecerían al territorio de la comunidad de Carampoma. Actualmente, estas dos comunidades se encuentran en juicio por este problema limítrofe (EE18).

\footnotetext{
${ }^{16}$ Hasta la fecha, estos proyectos no se han implementado debido a que fueron observados.

${ }^{17}$ Laguna concesionada a la empresa ENEL, con fines energéticos.

${ }^{18}$ Chaclla es el distrito más árido de la subcuenca. Se dedica principalmente a la ganadería.

${ }^{19}$ Hasta el momento, el presidente se mantiene debido a que fue reelegido por mayoría en dos ocasiones.

${ }^{20}$ Son las siglas de las Comunidades Campesinas de Collata, Chaclla, Huanza, Vicas, Jicamarca y Laraos.

${ }^{21}$ Son las siglas de las Comunidades Campesinas de Carampoma, Huachupampa, San Juan de Iris, Casta, San Mateo de Otao y Callahuanca.
} 
Figura 4. Mapa de ubicación del proyecto de irrigación

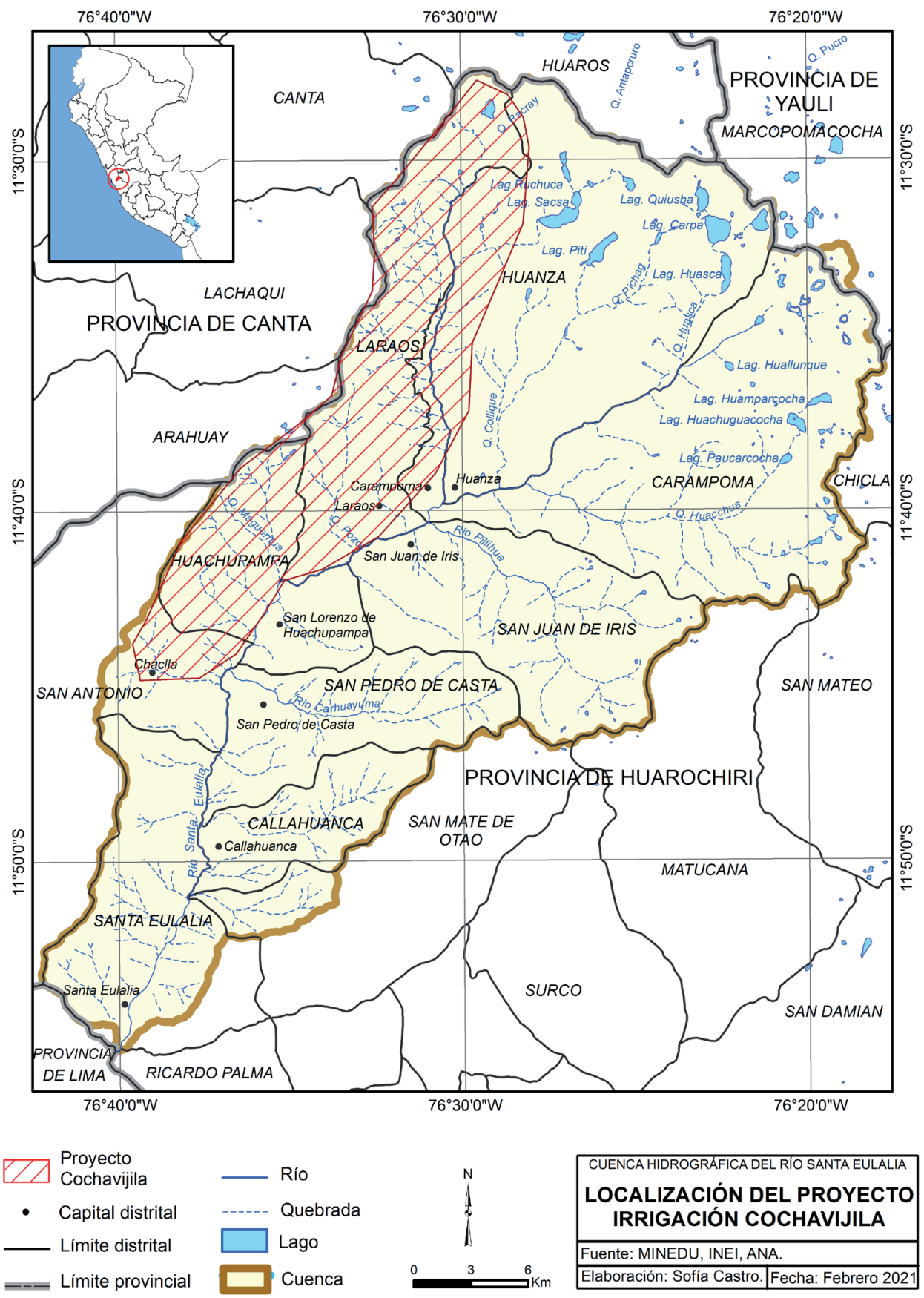


La ACCNH también tiene interés en captar agua de la laguna Quiulacocha, hacer diques para aumentar su capacidad y cosechar agua de lluvia, que beneficiará a las comunidades de Chaclla, Collata, Jicamarca, Vicas, la parte alta del distrito de Santa Eulalia y Laraos, e igualmente para mejorar la producción lechera (EE12). En términos territoriales, existe una superposición de proyectos de este con el proyecto «Sistema de riego Chinchan» de la MMVSE.

Antes de crearse oficialmente la ACCNH, las comunidades de la parte alta de la cuenca (Laraos, Carampoma y Huanza) se resistían a integrar esta asociación pues percibían que las comunidades ubicadas en la cuenca media y baja iban a beneficiarse del agua que proviene de sus fuentes de agua y tenían el temor de perder y competir por el agua. La oposición por este tema era muy fuerte, ya que las comunidades consideran que estas fuentes les pertenece por tradición. En los talleres que el PACyD de GWP realizó se mostraba que los beneficios de la conservación de las fuentes de agua traerían beneficios para todas las comunidades de la subcuenca y también para la ciudad de Lima (EE12, EE18, EE11). Los temores y tensiones al interior de la asociación continuaron, aunque sí se redujeron y cooperaron para su creación.

Otro tipo de tensiones al interior de la ACCNH son aquellas relacionadas con la superposición de los límites político-administrativos y los límites comunales, que no coinciden (ver mapa 3). Entre las comunidades campesinas de Callahuanca y la comunidad campesina de Casta, se encontró un conflicto existente. Una parte del territorio de la comunidad campesina de Casta, por el lado nor-este, está situado al interior de la delimitación administrativa-política del distrito de Callahuanca. La comunidad de Casta utiliza fuentes de agua para sus actividades productivas que están administrativamente dentro del distrito de Callahuanca. Por su parte, la comunidad de Callahuanca argumenta que ese territorio, históricamente, le pertenece, aún si los límites no están bien definidos, pero administrativa y comunalmente ese territorio le pertenece. Ambos quieren mantener y proteger su territorialidad, así como los recursos que se encuentran en él. Por su parte, la Municipalidad Distrital de Callahuanca no interviene en conflictos entre comunidades (EE14, EE15, EE18).

Las comunidades y las municipalidades, así como las asociaciones que los representan siempre han estado en constante tensión y poco diálogo. Un comunero al respecto señala:

hasta el 2010 yo llegaba a mi pueblo, llego a la subcuenca y las comunidades estaban así muriendo, todo sin información, sin detalles, todas las poblaciones esperábamos a los municipios, cada comunidad, cada distrito a su municipio, pero francamente nos han fallado pues, no han cumplido las obras y como ahora estamos todos los presidentes, me encuentro con todos los presidentes, algún alcalde hay? Ninguno, faltaba fuerza, coherencia de unirnos como estamos e intentarlo con las organizaciones institucionales que ya están trabajando pero falta municipio y va a seguir faltando por cuestiones presupuestales (Comunero de Casta durante el taller participativo. 23-06-2016). 
Figura 5. Mapa de superposición de límites distritales y comunales

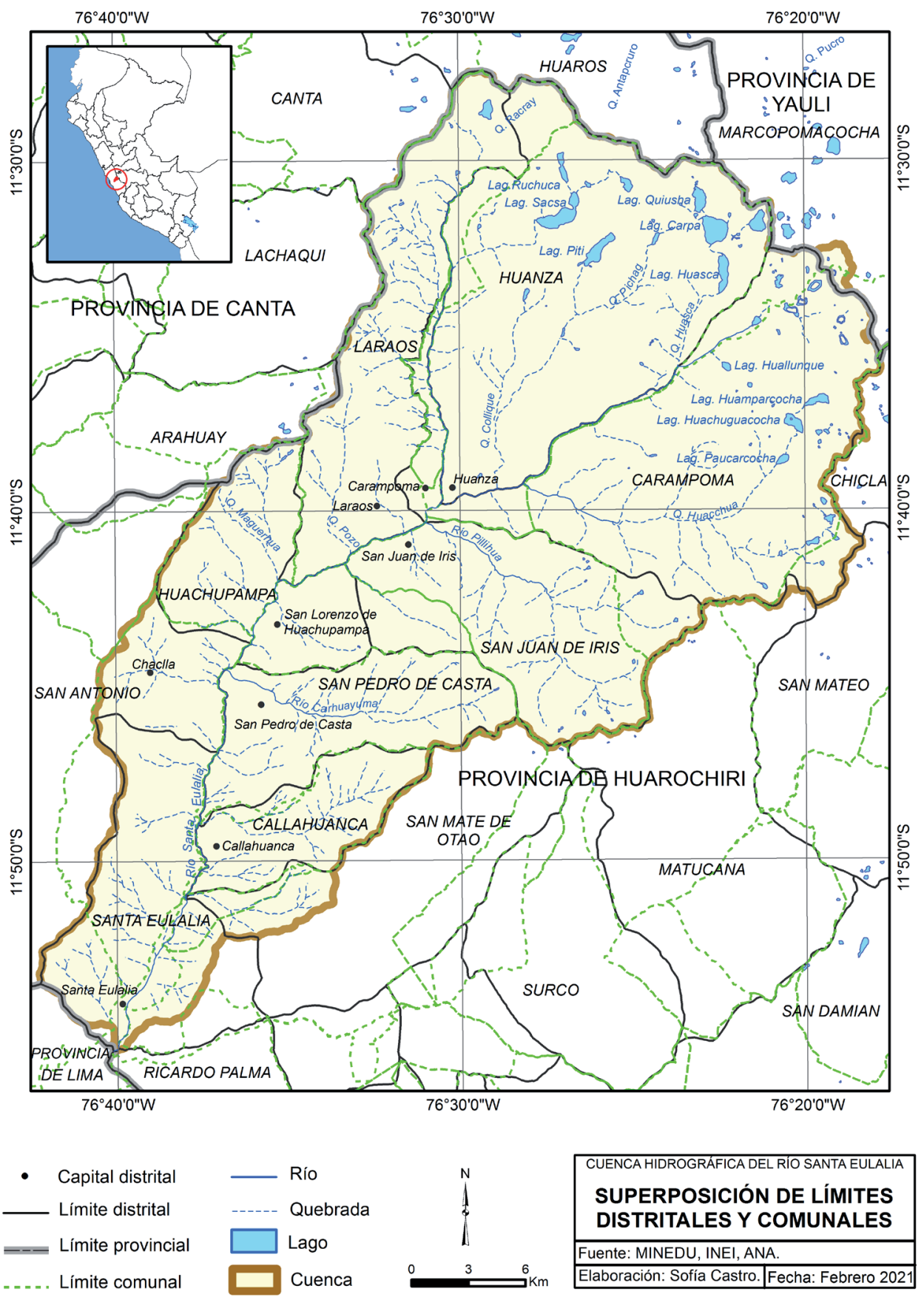


Las comunidades cuestionan permanentemente la legitimidad de los gobiernos locales ya que estos no responden a sus demandas y tienen una baja participación en las actividades de las comunidades. A partir del 2015, con el cambio de alcaldes en todo el país, la coordinación mejoró entre la MMVSE y la $\mathrm{ACCNH}^{22}$; hay un acercamiento y una mayor presencia de los líderes de ambas instituciones en diversos espacios de trabajo (ver figura 2) ${ }^{23}$ Este cambio se debe principalmente a tres factores: i) algunos alcaldes elegidos son miembros de las comunidades campesinas, ii) una mayor presencia de la Mancomunidad de Municipalidades del Valle de Santa Eulalia y la Asociación de Comunidades Campesinas Nor Huarochiri en diversos espacios de diálogo en la subcuenca y fuera de ella; y iii) el apoyo del PACyD en la subcuenca desde 2014, debido principalmente al fortalecimiento de capacidades de diversos actores locales en el tema de gestión integrada de recursos hídricos y de gobernanza.

Figura 6. Los actores involucrados en la subcuenca y el tipo de relaciones establecidas ${ }^{24}$
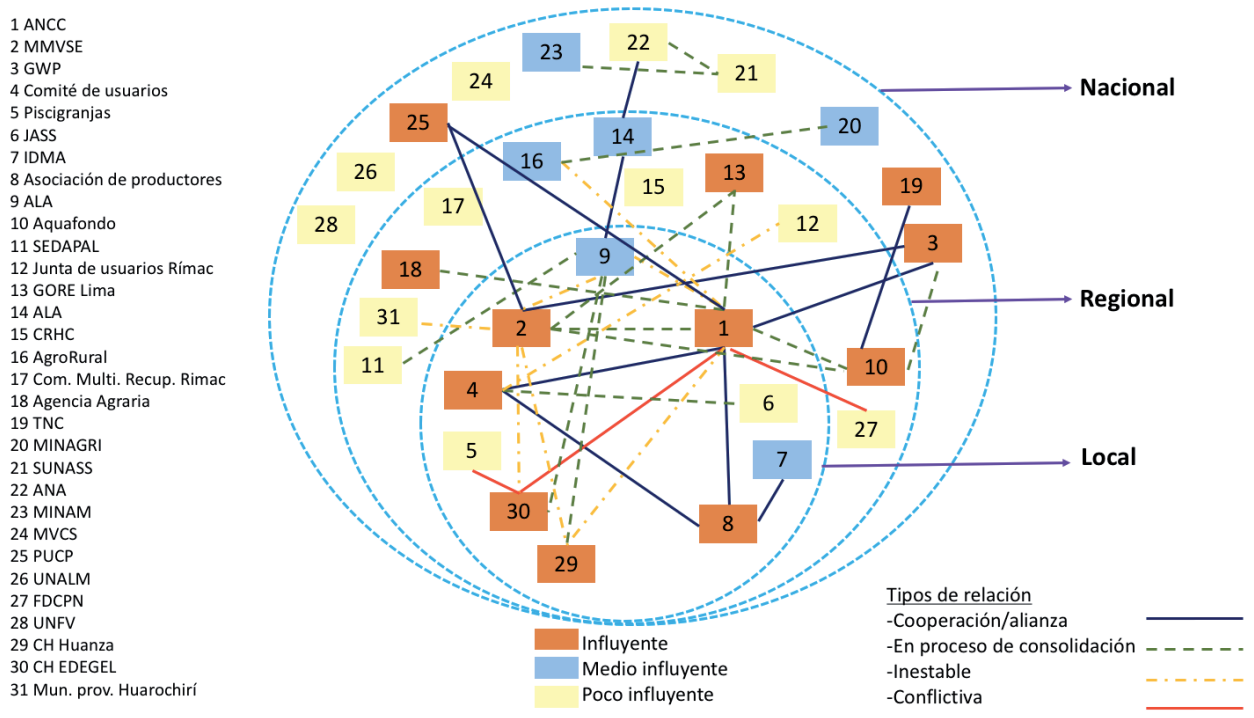

Fuente: Elaborado a partir del taller participativo organizado en el marco de la reunión del PACyD -GWP (23/06/2016).

${ }^{22}$ En esta época, aún no estaban formalizados como asociación.

${ }^{23}$ En la figura 2, [1] representa a la ACCNH y [2] a la MMVSE. La línea verde punteada significa que la relación «está en proceso de consolidación».

${ }^{24}$ El análisis de la figura 2, nos ayudará a comprender las relaciones de alianzas y de conflictos entre algunos actores de la subcuenca. Con el fin de no complicar el esquema de la figura 2, no vamos a analizar cada comunidad ni cada municipalidad, solo analizaremos a las dos organizaciones que las representan, aun cuando sabemos que, al interior de cada una de ellas, existen ciertas tensiones. 
A inicios de 2015, GWP organiza de manera conjunta con la MMVSE y la ACCNH un primer «Foro Interinstitucional» con el propósito de que ambas instituciones escuchen sus problemas, demandas y propuestas de acción. Dicho foro, culminó con un acuerdo firmado por todos los alcaldes de la subcuenca y los presidentes de las comunidades campesinas, donde reconocen la necesidad de trabajar de manera conjunta, coordinada y permanente para la organización de las acciones en la subcuenca. En aquella ocasión, ambas instituciones manifestaron su intención de construir un gran sistema de irrigación en la subcuenca. Sin embargo, cada uno siguió buscando su propio financiamiento y sus propios aliados para sus proyectos.

En el año 2016, se realizó el segundo Foro Interinstitucional, organizado enteramente por la MMVSE y la ACCNH con una agenda preparada conjuntamente y con el compromiso de fortalecer la relación entre ambos ${ }^{25}$.

\section{Foto 7. Primer Foro Interinstitucional (febrero, 2015)}

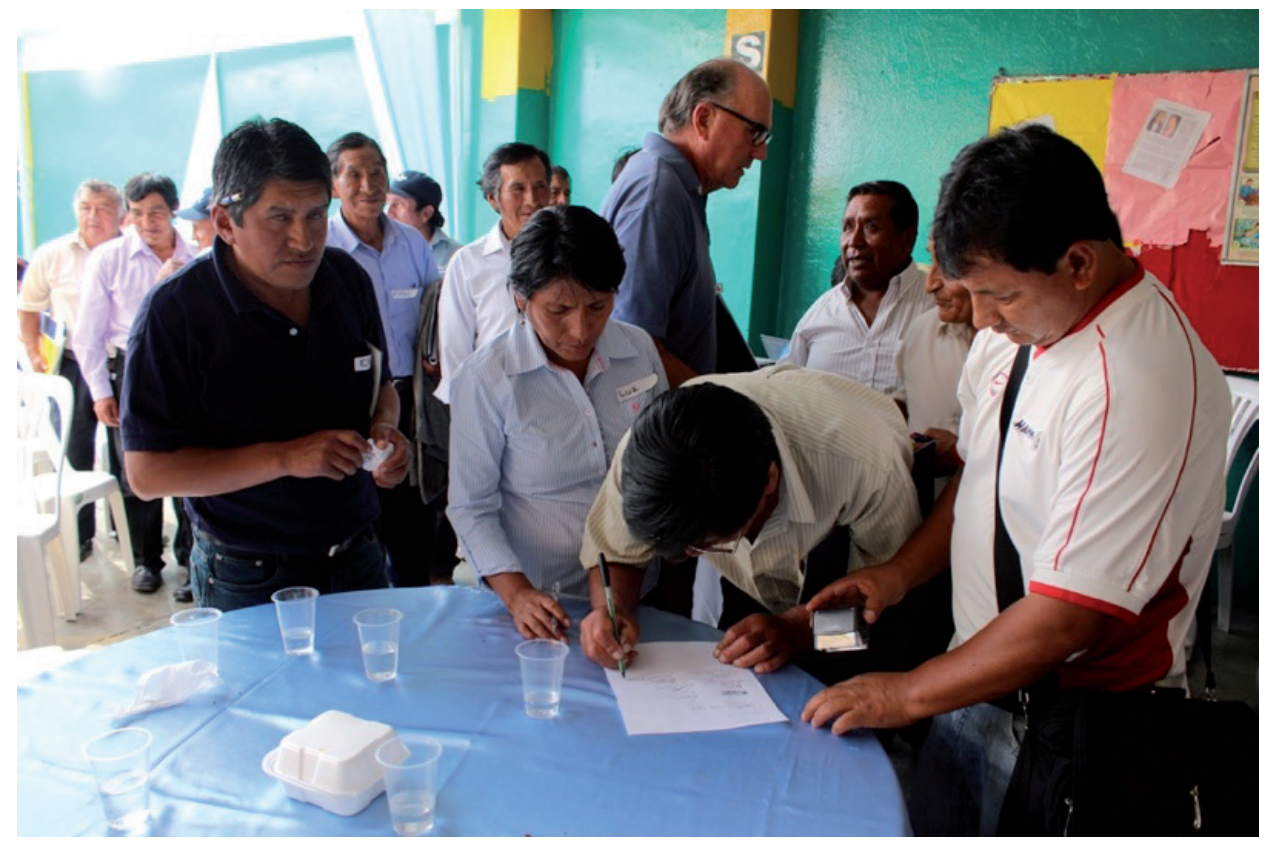

Fuente: archivo GWP (2015).

A pesar de los esfuerzos por lograr un acercamiento entre las municipalidades y las comunidades campesinas, todavía existen dificultades en la coordinación, entre estos últimos y los gobiernos locales; cada uno tiene su propia agenda y su propia visión de la subcuenca. Incluso, al interior de cada una de estas organizaciones, existen problemas de

${ }^{25}$ Este análisis se realiza sobre la base de observaciones personales durante el foro. 
integración y de coordinación. Otros puntos de desacuerdo son los tiempos y el tipo de intervención. Las comunidades critican a los gobiernos locales por realizar los proyectos de manera lenta y de realizar proyectos que no son prioritarios, así como la falta de transparencia y rendición de cuentas. A pesar de que los presupuestos participativos ofrecen un espacio de intercambio, de concertación y priorización de proyectos por parte de la población, son espacios con capacidades limitadas y un bajo impacto en el desarrollo de la subcuenca. Los comuneros argumentan que no reciben ayuda debido a la lejanía. Por su parte, los comuneros de Casta señalan que existe un divorcio con la municipalidad, no se ejecuta lo que se acuerda en los presupuestos participativos, lo mismo ocurre en la municipalidad de Santa Eulalia.

Los comuneros de Chaclla están permanentemente demandando apoyo del Municipio de San Antonio, donde pertenecen política y administrativamente, para resolver sus temas urgentes, como la escasez del agua para sus actividades productivas (ganadería). El centro de la Comunidad de Chaclla se encuentra al interior de la subcuenca de Santa Eulalia, pero la oficina de Municipalidad de San Antonio se encuentra fuera de la subcuenca desde hace quince ańos, cuando un alcalde decidió cambiar la sede del Municipio de San Antonio de Chaclla hacia el anexo o sector 8 de Jicamarca ${ }^{26}$ (fuera de la subcuenca).

Sin embargo, también hay autocríticas por parte de los mismos comuneros, por la inacción y la falta de seguimiento a sus propios acuerdos:

yo quisiera ahora hacer una autocrítica, aquí los presentes la municipalidad y las comunidades, todos los aliados estamos flojos, no hemos hecho nada referente a la gestión de mecanismo de la distribución de los servicios, el 22 de febrero del 2015 se llegó a un acuerdo, primero constituir al comité impulsor para gestiones de mecanismos para la distribución de los servicios en el sistema de Santa Eulalia, segundo nombrar un representante y así sucesivamente, no se hizo nada ni una sola reunión entonces es una crítica para todos nosotros (Comunero de San Juan de Iris durante el taller participativo. 23-06-2016)

El manejo del agua para riego en las comunidades campesinas se realiza a través de los comités de usuarios según sus propias normas de acuerdo con sus usos y costumbres. Con la nueva Ley de Recursos Hídricos de 2009, hubo un impulso para la formalización de los derechos de usos de agua por parte de la ANA. Estos comités no estaban formalizados, pero la mayoría de ellos obtuvo sus licencias de agua en una campaña del programa de formalización de derechos de usos de agua con fines agrarios a partir de 2016. Al inicio de esta campaña, las comunidades a través de sus comités se resistían a la formalización pues no entendían porque debían pagar por un recurso que por tradición lo han usado desde siempre. Estas campañas de formalización de la ANA fueron gratuitas.

\footnotetext{
${ }^{26}$ Ver también Mesclier, Piron y Gluski, 2015.
} 
Los comités realizan —ellos mismos- la operación y el mantenimiento de los canales, durante las champerías (fiestas del agua donde se realiza la limpieza y mantenimiento de los canales) (ver foto 3). En una misma comunidad, se puede tener varias comisiones y repartirse de acuerdo con la distribución de las fuentes de agua. La organización interna se decide al interior de cada comunidad (EE14, EE15, EE18).

Figura 8. «Champerías» en la Comunidad Campesina San Pedro de Casta

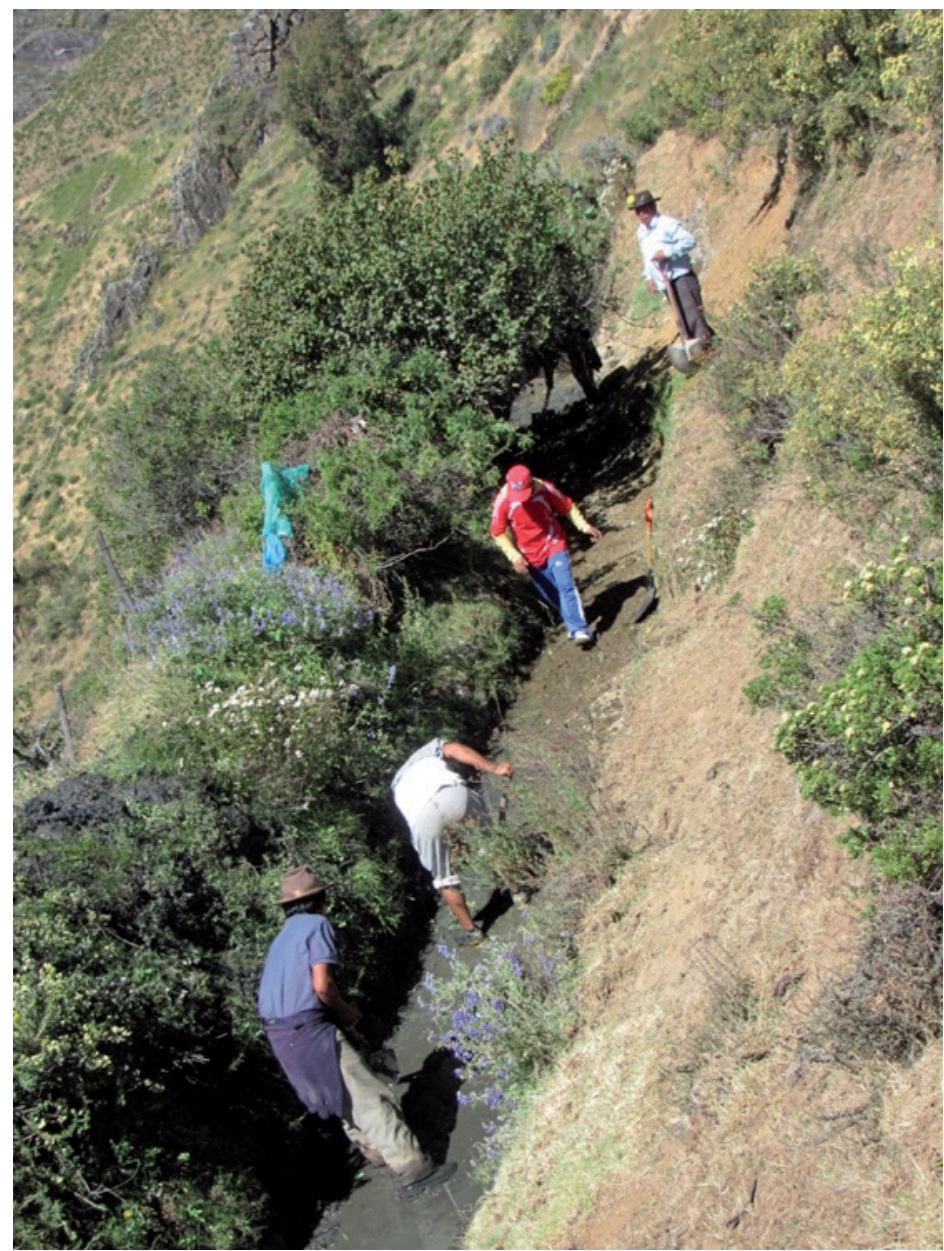

En la parte baja de la subcuenca, existen diez comités de usuarios de agua, pero no pertenecen a ninguna comunidad campesina, sino son parte del Comité de Regantes de Santa Eulalia con un aproximado de 375 usuarios, reconocido y formalizados también a través de las licencias de agua por parte de la ANA. Ellos son los encargados de la gestión del agua para riego y a su vez pertenecen a la Junta de usuarios del subdistrito 
de riego ${ }^{27}$ del río Rímac, responsable de la distribución del agua de este río para fines agrícola, así como de la operación y del mantenimiento de la infraestructura de riego de los comités de usuarios del agua, quienes se incluyen geográficamente en el distrito de riego del Chillón-Rímac-Lurín. ${ }^{28}$

La Junta de usuarios reciben el pago de una tarifa, el cual es utilizado para la operación y mantenimiento de los canales e infraestructura de irrigación (EE09, EE13). Según la ACCNH tiene una buena relación con los comités de usuarios de la subcuenca (línea azul en la figura 2).

La Autoridad Local del Agua (ALA) Chillón-Rímac-Lurín, es la responsable de otorgar las licencias de derecho de uso de agua con fines agrario y de coordinar con la Autoridad Administrativa del Agua (AAA) Cańete-Fortaleza y la ANA, pero su ámbito de acción se extiende más allá de la subcuenca. El trabajo realizado para la formalización de los derechos de uso de agua con fines agrarios es reconocido por los usuarios. Sin embargo, los comités de usuarios trabajan de manera individual, sin ninguna coordinación con la ALA. En 2014, cuando la ALA comenzó a realizar los primeros talleres de sensibilización sobre la formalización de los derechos de uso de agua, los usuarios se oponían, ya que no visualizaban los beneficios que ellos podrían obtener de este proceso y al contrario, lo percibían como una obligación para acceder a otros programas del Estado ${ }^{29}$.

Sin embargo, esta percepción ha cambiado y ahora demandan que la ALA continúe con el programa de formalización de los derechos de uso del agua en la subcuenca. Si bien los actores locales tienen una fuerte influencia en sus propios territorios, a medida que se alejen y pasen a otras escalas (provinciales o nacionales), sus influencias son cada vez menores. La percepción de los actores es que no existe una relación directa entre la ALA (órgano desconcentrado de la ANA) con la MMVSE o la ACCNH.

Como se mencionó líneas arriba, la subcuenca concentra recursos estratégicos para la capital del país, primero el agua destinada al consumo de la población y luego la energía que alimenta al sistema energético integrado nacional (SEIN) que luego distribuye a todo el país. Se estima que la subcuenca provee el $72 \%$ de la energía a la metrópoli (EE06). La empresa de Servicio de Agua Potable y alcantarillado de Lima (Sedapal) y las empresas privadas, en particular ENEL ${ }^{30}$ (con dos centrales hidroeléctricas en la subcuenca) y CONENHUA (opera una central en la subcuenca) están involucradas

\footnotetext{
${ }^{27}$ El distrito de riego no forma parte de un distrito político-administrativo. Esta delimitación viene de una antigua norma (artículo 54 del Decreto Legislativo 653 de 1991), en el que se señala que el MINAG determinaba el ámbito de cada distrito de riego, sobre la base de la realidad de cada cuenca hidrográfica y las necesidades de la eficiente administración del recurso agua.

${ }^{28} \mathrm{http}: / /$ www.jurimac.com

${ }^{29}$ Este análisis se realiza sobre la base de observaciones personales y de algunas personas entrevistadas.

${ }^{30}$ Nueva empresa hidroeléctrica quien compró a Edegel.
} 
en la gestión de los recursos hídricos. Sedapal, está muy interesada en facilitar los mecanismos de retribución o pago por los servicios ecosistémicos en las tres cuencas de Lima a través del Programa Sembramos Agua, ${ }^{31}$ creado en 2017 con el fin de asegurar la disponibilidad hídrica necesaria para su propio funcionamiento.

Las centrales hidroeléctricas ocupan una parte del territorio de la subcuenca (ver mapa 1) y utilizan directamente el agua del río. En la actualidad, se encuentran operando tres centrales en la subcuenca: Huanza (empresa CONENHUA), Huinco y Callahuanca (ENEL). Esta última tiene dos centrales hidroeléctricas con una capacidad promedio de potencia efectiva de 327 MegaWatts (Edegel, 2014). Para poder generar esa energía, la empresa desvió el agua y captó fuentes de agua de algunas comunidades de las alturas y en su reemplazo construyó "ventanas de agua»" ${ }^{32}$. La empresa ENEL, realiza un pago por el uso del agua. Este dinero está destinado a las comunidades y distritos de la parte alta de la subcuenca (EE11, EE12, EE18). Sin embargo, existe un problema con los agricultores que riegan la parte baja, ya que la empresa ha establecido ciertas horas de cierre del agua para la parte baja de la subcuenca (entre las 5 a.m. y $12 \mathrm{~m}$.), luego del cual entrega el agua a través de estas ventanas (EE12).

De otro lado, algunos regantes señalan que el problema del agua de riego es que se desperdicia debido a que no realizan mantenimiento en sus canales. Asimismo, a pesar de la ausencia de estudios por parte de las autoridades responsables de ello, los habitantes están preocupados ya que cada 8-9 meses, las compuertas de los vertimientos son abiertas ocasionando numerosos impactos en la parte baja de la cuenca (EE06). Esto preocupa a la población, quienes temen por los impactos en el ecosistema y también en la cantidad de agua disponible para sus actividades productivas (EE12, EE18).

La relación entre los miembros de las comunidades, los regantes de la parte alta de un lado y ENEL de otro lado, es frecuentemente conflictiva (ver línea roja de la figura 2 entre los actores [1] y [30]) ya que ellos afirman que en algunas localidades reciben poca cantidad de agua en los momentos previstos donde las centrales deben liberar agua con el fin de que los pobladores puedan disponer del agua para fines domésticos y agrícolas (EE12, EE18). ENEL mantiene una buena comunicación con los distritos donde se sitúa su infraestructura (parte alta de la subcuenca) ya que las municipalidades reciben el dinero por el uso de las fuentes de agua (canon del agua), el cual contribuye también a su presupuesto (EE18), pero la relación con los actores (principalmente los productores) de la parte media y baja son tensas.

\footnotetext{
${ }^{31}$ El programa implementará proyectos ecosistémicos que permitan recuperar y conservar las cuencas de los ríos Chillón, Rímac, Lurín, a partir de un fondo en base al 1\% de la tarifa cobrada a los usuarios de Sedapal. Este financiamiento es fiscalizado por la Superintendencia Nacional de Servicios de Saneamiento (Sunass).

${ }^{32}$ Son infraestructuras como túneles para la entrega de agua en la parte media y baja de la subcuenca.
} 
Sedapal y ENEL son actores influyentes quienes son responsables de la operación y la gestión de las grandes infraestructuras hidráulicas (trasvase, canales y represas); por ello, la gestión del río Santa Eulalia así como las lagunas de las partes altas es regulada. $\mathrm{Al}$ mismo tiempo, estas instituciones participan en las coordinaciones de la Comisión Multisectorial de Recuperación del Río Rímac y también como usuarios no agrarios del CRHC CHIRILU. Cabe señalar que ENEL no participa en el Comité de PACyD, a pesar de las reiteradas invitaciones que se le ha hecho.

Los gobiernos regionales, dentro del proceso de transferencia de funciones, recibió algunas competencias vinculadas a la gestión de los recursos hídricos. El Gobierno Regional de Lima señala no poder aplicar dichas funciones debido a la falta de recursos y de asistencia técnica (EE10), por lo que siempre depende y solicita apoyo al gobierno central para algunos proyectos. La MMVSE y la ACCNH señalan que existe una buena relación (línea verde) así como la voluntad del gobierno regional para apoyarlos en el desarrollo local (EE11, EE12, EE18).

La Agencia Agraria de Santa Eulalia [18], oficina que depende del Gobierno Regional de Lima, es un actor influyente para la ACCNH (línea verde punteada) debido al apoyo que reciben para sus actividades productivas. Cuenta con una oficina en Santa Eulalia, compartida con Agrorural (MINAGRI). Su principal función es promover el desarrollo agropecuario y realizar diferentes acciones como por ejemplo la formación para el mejoramiento del ganado y técnicas agrarias, el apoyo a las organizaciones de productores, la distribución de plantones para (re)forestación (la agencia cuenta con un vivero propio en Santa Eulalia).

AGRO RURAL [16], unidad ejecutora del Ministerio de Agricultura y Riego (MINAGRI) tiene por objetivo promover el desarrollo agrícola rural, a través del financiamiento de proyectos de inversión pública en zonas rurales de menor grado de desarrollo económico. Esta institución brinda asistencia técnica e implementa proyectos de irrigación, así como de infraestructura verde (siembra y cosecha de agua) (EE05). La relación con la ACCNH no es permanente, salvo exista algún proyecto particular (línea naranja)

A nivel de la cuenca del Rímac, tenemos la "Comisión Multisectorial para la Recuperación de la calidad de los Recursos Hídricos de la cuenca del río Rímac» creada en $2012^{33}$ con el interés de resolver la problemática de contaminación del río Rímac, así como en la integración de otros actores claves, como el Gobierno Regional de Lima Metropolitana, el Gobierno Regional del Callao, el Gobierno Regional Provincial de Lima, el Gobierno Regional Provincial de Huarochiri, etc (EE01). En junio de 2016,

\footnotetext{
${ }^{33}$ Decreto Supremo 022-2012-AG.
} 
se creó el Consejo de Recursos Hídricos de Cuenca $^{34}$ del Rímac, Chillón y Lurín (CHIRILU). Hasta el momento del trabajo de campo no se había instalado su directorio, en la actualidad, el CRHC funciona y está en pleno proceso de elaboración de su plan de gestión para las tres cuencas.

Otro actor clave es Aquafondo ${ }^{35}$ [10], un mecanismo financiero que moviliza fondos para la conservación de las tres cuencas de Lima. Esta institución es responsable de un proyecto sobre la adaptación al cambio climático en la subcuenca de Santa Eulalia. Fue facilitador del Grupo Impulsor para la conformación del Consejo de Recursos Hídricos CHIRILU. Actualmente, apoya a las comunidades de las tres cuencas en proyectos de infraestructura natural como recuperación de amunas y zanjas de infiltración. Su relación con las comunidades se consolida cada vez más.

A nivel nacional, podemos observar que los ministerios como MINAGRI y MINAM tienen poca influencia en la subcuenca. En cuanto a MINAGRI, los productores le demandan permanentemente apoyo, especialmente para suministrarles forraje para sus animales, sobre todo en la época de sequía prolongada y severa como ocurrió en el 2016. La relación con la ACCNH no es directa sino a través de Agrorural. Por su parte, MINAM, organismo del estado responsable del ambiente y de la mejora de la calidad de vida de las personas, garantizando la existencia de ecosistemas saludables; y el desarrollo sostenible del país. Está presente en la subcuenca a través de talleres de sensibilización sobre lucha contra la desertificación y sequía. El Ministerio de Vivienda, Construcción y Saneamiento (MVCS) tiene un rol clave en relación con los servicios de agua potable y saneamiento. Ellos deben intervenir desde su programa Nacional de Saneamiento Rural, pero es el gran ausente en la subcuenca ${ }^{36}$.

De acuerdo con el análisis de actores, podemos seńalar que los principales conflictos se producen a nivel local por el uso del recurso hídrico, por la cantidad utilizada, la calidad y el tiempo de uso. A pesar de que existen diversas alianzas, algunas inestables y otras en proceso de consolidación, es importante la resolución de estos conflictos a fin de no afectar la gestión del agua y la relación entre los otros actores. Esto nos muestra que el cambio más importante no es la aprobación de una nueva legislación en la gestión del agua sino como pasar de una organización local, sectorial hacia una gestión compartida y coordinada con otros usuarios (Ghiotti, 2006; Kassibo, 2002).

\footnotetext{
${ }^{34}$ Son espacios institucionales de diálogo, donde los actores relacionados a la gestión del agua en las cuencas discuten sus problemas a fin de llegar a consensos, tomando acuerdos y comprometiéndose con la implementación de las acciones en sus respectivas cuencas. A través del consejo, los actores de la cuenca participan en la planificación, coordinación y concertación para el aprovechamiento sostenible de los recursos hídricos en sus respectivos ámbitos, mediante el Plan de Gestión de Recursos Hídricos en la Cuenca (Fuente: https://www.ana.gob.pe/nosotros/planificacion-hidrica/plan-gestion-cuencas).

35 http://aquafondo.org.pe/que-hacemos/nuestros-proyectos/

${ }^{36}$ Este análisis se realiza sobre la base de observaciones personales durante el taller de GWP.
} 


\section{REFLEXIONES A MODO DE CONCLUSIÓN}

Después de la implementación de la ley de recursos hídricos de 2009, la malla institucional se ha tornado más compleja debido a la diversidad de usos (agrícola, urbano, industrial, turístico) y de las diferentes instancias de gestión (público, privado y comunal); de ahí que la gobernanza ${ }^{37}$ es un verdadero desafío para hacer frente a la complejidad de la gestión, sobre todo en un territorio donde observamos que el agua se comparte y se compite entre tres usuarios de agua, principalmente: agrícola, energético y poblacional.

Esto lleva a que las relaciones de poder se muestren muy visibles en este territorio, donde el agua es un recurso cuya competencia es alta debido a la cantidad de usuarios del agua, pero también por las percepciones de algunos usuarios en relación con la calidad y el tiempo de uso del recurso. Estos conflictos muestran las relaciones de poder entre la parte alta y baja de la cuenca por las competencias y demandas de agua.

El principio de descentralización en la gestión del agua, tal como se promueve en la ley de recursos hídricos, otorga a los territorios de agua un grado de autonomía en lo que respecta al recurso, en el control de los planes de gestión del agua y en la participación del gobierno local, de la sociedad civil y de los miembros de las comunidades campesinas. En el caso de la subcuenca Santa Eulalia, podemos observar que los comités de usuarios de agua de las comunidades tienen cierta autonomía en cuanto al manejo y control del recurso porque siempre lo han manejado así, pero los comités de riego siempre dependen de la Junta de usuarios para su operación y mantenimiento y este a su vez del plan de aprovechamiento hídrico que se acuerda con la ANA junto a los usuarios agrícolas, energético y poblacional.

El caso de Santa Eulalia nos permite observar también desafíos territoriales muy importantes. De un lado, los problemas de superposición de los límites entre los territorios de las comunidades campesinas y de los gobiernos locales y los límites de la subcuenca. Sus límites no coinciden entre ellos y en algunos casos, los territorios de las comunidades campesinas o de los gobiernos locales se extienden más allá de la subcuenca. De otro lado, la superposición de proyectos para llevar más agua hacia lugares más áridos nos demuestra que el fondo del debate es el mantenimiento y la protección de las territorialidades y las fuentes de sus recursos hídricos, así como la necesidad de algunas comunidades de acceder a otras fuentes de agua, ya que el agua del río no es suficiente para sus fines productivos.

La participación en los espacios multiactor y multinivel, como es el caso de la plataforma creada por el PACyD de GWP, es mayor y ha fortalecido a algunas comunidades y municipios. Esto ha permitido una coordinación entre los actores en diversas escalas

\footnotetext{
${ }^{37}$ De acuerdo con la definición de Mazurek (2009, p. 13), la gobernanza es la «mejora de la eficacia de las instituciones democráticas y políticas, al aprovechar, particularmente, de la aparición de nuevas formas de poderes locales».
} 
y una generación de alianzas, pero aún necesita ser fortalecida pues siguen primando las agendas individuales de los poderes locales.

Los conflictos muestran que los poderes locales tienen diversos intereses en juego, como la legitimación y el control de su territorialidad y los recursos presentes, en particular el agua. Los procesos dinámicos — tal como las migraciones, el crecimiento comercial y turístico en la parte baja de la subcuenca, los efectos del cambio climático, entre otros - refuerzan un escenario incierto para el desarrollo local de la subcuenca y se traducen a la vez en más conflictos territoriales y en dificultades de coordinación entre los diferentes actores (Dubresson \& Fauré, 2005).

El rol de la MMVSE y la ACCNH es clave en la gestión coordinada de la subcuenca, aunque hasta el momento aún no es posible una real concertación. Podemos observar que los actores de la subcuenca tienen diversos intereses sobre su territorio y sobre los usos del agua. Cada actor tiene por objetivo satisfacer sus propias necesidades con los recursos que tiene. En ese sentido, la organización del espacio en la subcuenca de Santa Eulalia impide una visión compartida del desarrollo, para encontrar soluciones concertadas y realizar esfuerzos conjuntos.

El rol de GWP a través de su programa PACyD es fundamental, ya que ha permitido acercar diversas instituciones del estado y del sector privado para interactuar con los actores locales. Su importancia aumentó después que la ANA formalizó al conjunto de instituciones públicas y privadas en un Grupo de Trabajo Especializado para la elaboración de una estrategia de gestión integrada de recurso hídricos de la subcuenca. Sin embargo, ¿̨nos queda la interrogante si esta integración y esta nueva forma de crear nuevas escalas de coordinación facilita efectivamente la gestión? Es verdad que existe una "voluntad» de articular y de coordinar, pero no es suficiente... nos preguntamos entonces ¡cuáles son los factores que ayudan a tener una mejor coordinación entre todos los actores en diferentes escalas?

\section{REFERENCIAS}

Andersson, K. P. \& Ostrom, E. (2008). Analyzing decentralized resource regimes from a polycentric perspective. Policy Sciences, 41(1), 71-93. https://doi.org/10.1007/ s11077-007-9055-6

Bey, M. (2010). Réformes néolibérales et tensions sur les ressources dans la décentralisation au Pérou et au Mexique. Revue internationale de politique comparée, 17(3), 127-142. https://doi.org/10.3917/ripc.173.0127

Castro, S. (2016). Gestion de l'eau et décentralisation. Le cas de la rivière Santa Eulalia à la peripherie de la métropole de Lima (Pérou). Université Paris 1 Panthéon-Sorbonne, Mémoire de M2 Pays émergents et en développement, sous la direction de Evelyne Mesclier. 
Charnay, B. (2010). Pour une gestion intégrée des ressources en eau sur un territoire de montagne. Le cas du bassin versant du Giffre (Haute-Savoie) [Phdthesis, Université de Savoie]. https://tel.archives-ouvertes.fr/tel-00472979/document

Dubresson, A. \& Fauré, Y.-A. (2005). Décentralisation et développement local: Un lien à penser. Tiers-Monde, 46(181), 7-20. https://doi.org/10.3406/tiers.2005.5900

Edegel. (2014). Memoria Anual e Informe de Sostenibilidad 2014. http://www.edegel.com/ ES/CONOCENOS/Memorias/Memoria\%20de\%20Edegel\%202014.pdf

Edelenbos, J. \& Teisman, G. R. (2011). Numéro spécial sur la gouvernance de l'eau. Revue Internationale des Sciences Administratives, 77(1), 5-30. https://doi.org/10.3917/ risa.771.0005

Ghiotti, S. (2006). Les Territoires de l'eau et la décentralisation. La gouvernance de bassin versant ou les limites d'une évidence. Développement durable et territoires. Économie, géographie, politique, droit, sociologie, Dossier 6. https://doi.org/10.4000/developpementdurable. 1742

GWP. (2000). La gestion intégrée des ressources en eau. http://www.gwp.org/Global/ToolBox/ Publications/Background\%20papers/04\%20Integrated\%20Water\%20Resources\%20 Management\%20(2000)\%20French.pdf

Haghe, J. P. \& Ghiotti, S. (2004). Bassin versant et politique de décentralisation: Une instrumentalisation? CyberGeo.

Harvey, D. (1998). La condición de la posmodernidad: Investigación sobre los orígenes del cambio cultural. Amorrortu.

INEI. (2016, January 15). Cerca de 10 millones de personas viven en Lima Metropolitana. Instituto Nacional de Estadistica e Informática. https:/www.inei.gob.pe/prensa/ noticias/cerca-de-10-millones-de-personas-viven-en-lima-metropolitana-8818/

Kassibo, B. (2002). Priorités nationales et intérêt local. Des grands barrages à la décentralisation. En D. Orange, R. Arfi, M. Kuker, P. Morand \& Y. Poncet (eds.), Gestion integree des ressources naturelles en zones inondables tropicales (pp. 119-130). IRD. https://doi.org/10.4000/books.irdeditions.8519

MINAM. (2013). Agenda Ambiental 2013-2014. Recuperado de http://www.minam.gob. pe/wp-content/uploads/2013/06/agendambiental_peru_2013-20141.pdf

Perez-Sanchez, J. \& Senent-Aparicio, J. (2015). Integrated water resources management on a local scale: A challenge for the user community a case study in Southern Spain. Environmental Earth Sciences, 74(7), 6097-6109. https://doi.org/10.1007/ s12665-015-4633-y

Trottier, J. (2008). Water crises: Political construction or physical reality? Contemporary Politics, 14(2), 197-214. https://doi.org/10.1080/13569770802176929

World Economic Forum. (2020). The Global Risks Report 2020. Recuperado de https:// www.weforum.org/reports/the-global-risks-report-2020/ 
Zegarra, E. (2005). Planificación y administración hídrica en Perú. En A. Jouravlev (ed.), Administración del agua en América Latina: Situación actual y perspectivas (pp. 49-54). Naciones Unidas, CEPAL. Recuperado de https://www.cepal.org/es/ publicaciones/6282-administracion-agua-america-latina-situacion-actual-perspectivas 